\title{
Bertholène, Flavin, Laissac et Palmas
}

\section{(Q) OpenEdition \\ Journals}

Édition électronique

URL : http://journals.openedition.org/adlfi/10523

ISSN : 2114-0502

Éditeur

Ministère de la culture

Référence électronique

"Bertholène, Flavin, Laissac et Palmas », ADLFI. Archéologie de la France - Informations [En ligne], MidiPyrénées, mis en ligne le 01 mars 1997, consulté le 03 mai 2019. URL : http://

journals.openedition.org/adlfi/10523

Ce document a été généré automatiquement le 3 mai 2019.

(C) Ministère de la Culture et de la Communication, CNRS 


\section{Bertholène, Flavin, Laissac et Palmas}

Date de l'opération : 1991 (PI)

Inventeur(s) : Joyes Raymond

1 Dans le but d'y reconnaître des industries paléolithiques associées, Raymond Joyes a entrepris la cartographie et la prospection des formations alluviales des bassins de l'Aveyron et du Viaur.

2 Dans un premier temps, il s'est essentiellement attaché au secteur localisé en amont de Rodez, plus précisément situé le long d'un ancien lit de l'Aveyron recoupant les communes de Laissac, Palmas et surtout de Bertholène. Les dépôts s'étagent entre $640 \mathrm{~m}-625 \mathrm{~m}$ (nappe culminante à $+60 \mathrm{~m}-80 \mathrm{~m})$ et $575 \mathrm{~m}(+10-15 \mathrm{~m})$ correspondant au premier niveau au-dessus du lit actuel.

3 Plus au sud, une série de nappes de galets à patine rousse ou lie de vin, étagées entre $620 \mathrm{~m}$ et $705 \mathrm{~m}$ ont également été prospectées dans la zone d'interfluve, entre Aveyron et Viaur (commune de Flavin).

Dans un tel contexte, le principal matériau accessible pour les Néandertaliens et leurs prédécesseurs était le quartz. C'est uniquement dans le premier secteur (Bertholène) que l'auteur a jusqu'à présent pu identifier des éclats et des galets aménagés en quartz ( choppers, nucléus, etc.), roche ingrate pour laquelle se pose souvent la question d'une interprétation anthropique. 
INDEX

Index chronologique : Paléolithique inférieur, Paléolithique moyen operation Prospection inventaire (PI) 